\title{
Assessment of Thermal Environment in a Kitchen with a New Ventilation System
}

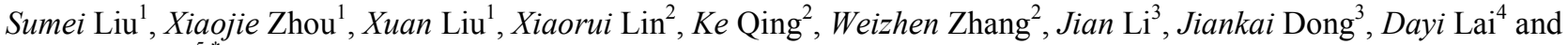 \\ Qingyan Chen ${ }^{5}$ * \\ ${ }^{1}$ School of Environmental Science and Engineering, Tianjin University, Tianjin, 300072, China \\ ${ }^{2}$ Vanke real estate development co. Itd, Changsha Vanke, Hunan Province, 410000, China \\ ${ }^{3}$ School of Architecture, Harbin Institute of Technology, Heilongjiang Province, 150006, China \\ ${ }^{4}$ Department of Architecture, School of Design, Shanghai Jiaotong University, Shanghai, 200240, China \\ ${ }^{5}$ School of Mechanical Engineering, Purdue University, West Lafayette, IN 47905, USA
}

\begin{abstract}
Chinese kitchen environment is usually hot and humid in summer and cold in winter, while housewife spends considerable time there. This investigation developed a new ventilation system for Chinese kitchens to improve thermal comfort level. To assess the thermal performance of the ventilation system, 32 cooks were asked to prepare the same dishes in the kitchen with or without the system in summer in Changsha, China. The assessment was carried out by subjective questionnaire survey on thermal sensation vote (TSV) and objective on-site measurements of the indoor air temperature and cook's skin temperature. The indoor air temperature was measured at different locations in the kitchen. The skin temperature was measured at 18 body parts of the cooks. The results show that the thermal environment in the kitchen was non-uniform and local thermal sensation had a great influence on the whole body sensation. Without the new ventilation system, the cooks complained that the hottest parts were thorax, head and face areas. Reasonably good correlation existed between the cooks' skin temperatures and their thermal sensation votes. The increase of cooks' skin temperature with the ventilation system was lower than that without the ventilation system. TSV was improved with the new ventilation system.
\end{abstract}

\section{Introduction}

As an important daily activity, housewife spends considerable time in the domestic kitchen [1,2]. Thus, residential kitchen should be thermally comfortable. Acceptable thermal comfort criteria are defined in international standard EN ISO 14505 [3] from Europe and ASHRAE Standard 55 (2013) [4]. However, those two standards are intended for buildings where its thermal environment is steady and uniform with sedentary or near-sedentary activity levels. Kitchen environment presents a much broader range of conditions than those that occurs in offices and living rooms. Due to high activity levels and dynamic thermal environment in Chinese kitchens, these comfort standards may not be applicable to the kitchens.

The thermal environment in a residential kitchen in China is transient and non-uniform and with strong radiation asymmetry due to the use of gas stove. Typical Chinese cooking includes frying, stir-frying, stew, steaming, etc., and the use of high power gas stove will generate a lot of heat, which will deteriorate the thermal environment in the kitchen [5]. The radiant heat is particularly strong in hot summer. Precious study showed that an exhaust hood could not effectively remove the waste heat in the kitchen [6]. And an increase of temperature of $5.5^{\circ} \mathrm{C}$ above the thermally neutral level may result in a $30 \%$ loss of productivity [7]. Zhao et al. measured indoor air temperature in residential kitchen to be $10.3^{\circ} \mathrm{C}$ higher than that outdoors during cooking [8]. Since most Chinese kitchens are not conditioned in summer and there is no organized makeup air system, the thermal environment and indoor air quality are not good. Therefore, it is important to understand the thermal environment, human thermoregulation, and perception of thermal comfort in the kitchen environment, and propose reasonable measures to improve the thermal environment in the kitchen.

Early studies on thermal comfort in kitchens mainly focused on the commercial kitchens. Livchak et al. investigated the commercial kitchen environment and found that the chest and facial areas had the greatest exposure to temperature differences. Additionally, the greatest heat loads were encountered at the cooking line, which produced the largest heat gains in the space, and where the workers were exposed to the highest temperatures [9]. Simone et al. investigated the thermal environment in more than 100 commercial kitchens in the United States in both summer and winter. They found that even if all kitchens were provided with airconditioning systems, indoor air temperature was much

Corresponding author: yanchen@purdue.edu 
higher than expected. The highest temperature in the cooking zones could reach up to $41.2^{\circ} \mathrm{C}$ [10].

A number of other studies in the residential kitchen mainly focused on the air quality and measures to improve the indoor air quality $[11,12]$. Even with an exhaust hood, significant high contaminant level in the breathing zone exists during cooking [8]. Cao et al. investigated the effectiveness of local make-up air for reducing individual exposure level. They found that well-organized local make-up airflow could reduce one's exposure to the cooking-generated particles in Chinese residential kitchens [13].

Previous studies have not determined how the thermal environment in the residential kitchen affects human thermal comfort and how to improve its thermal environment. This investigation developed a new ventilation system for Chinese kitchens to improve its thermal comfort level. Human subject tests were conducted to assess its thermal performance.

\section{Methods}

This section describes the schematically the new ventilation system, the experimental design to assess the thermal performance of the new ventilation system, as well as the measured parameters for the subject tests.

\subsection{Description of the new ventilation system}

This investigation developed a new ventilation system for Chinese kitchens to improve thermal comfort level. The system supplied conditioned air from the lower part of cabinet under the cooking stove and makeup air from the two sides and the front edge of the stove. The cook fume was exhausted from the hood above the stove as shown in Figure 1.

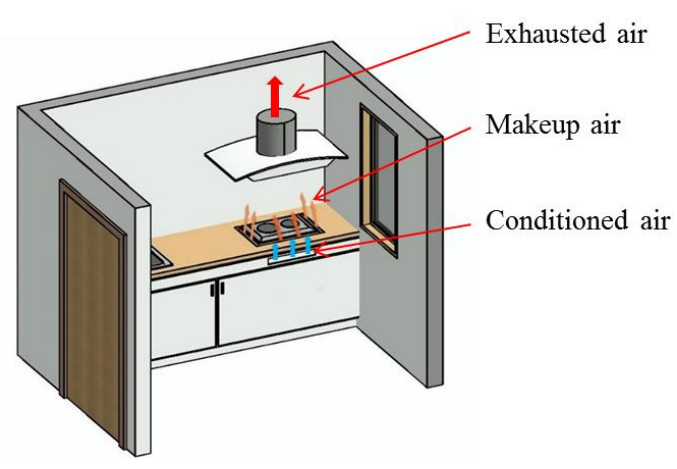

Fig. 1. The schematic of the ventilation system.

\subsection{Experimental design and procedure}

To assess the thermal performance of the new ventilation system, experimental tests were conducted in two identical kitchens with or without the system in Changsha, China. The kitchen size was $2.9 \mathrm{~m}(\mathrm{~L}) \times 1.85 \mathrm{~m}$ (W) $\times 2.3 \mathrm{~m}(\mathrm{H})$. Sixteen subjects, 9 male and 7 female with an average age of 22 (standard deviation $=4$ ), participated in the tests. We used the same subjects repeatedly for the two test conditions with or without the new ventilation system. Each subject was asked to cook two same dishes (one capsicum fried with meat and the other stir-fried vegetables) in the two kitchens for a total of 32 tests. This investigation conducted subjective questionnaire survey on thermal sensation vote (TSV) and objective on-site measurements of the indoor air temperature and cook's skin temperature $\left(\mathrm{T}_{\mathrm{sk}}\right)$.

Each test took about one hour. The experimental process was as follows: Before each test, the external window and interior door were opened and a portable vertical fan in the kitchen and the exhaust hood were turned on about 20 minutes. This is to ensure the kitchen started with a non-conditioned status as most Chinese residential kitchens. After this time, the window and door of the kitchen will be closed for 10 minutes. The total preparation time for the kitchen was 30 minutes. At the same time, we asked the subject to stay at a preparation room with an ambient temperature close to $26^{\circ} \mathrm{C}$ for 30 minutes to achieve a neutral thermal state. During their stay in the room, all the subjects were briefed on the experimental procedure and taped the wireless button thermometers on their skin. After they reached the thermal neutral status, they went to the kitchen and started the experiment. For the kitchen with ventilation system, the air-conditioning system was operated immediately with supply temperature of $18^{\circ} \mathrm{C}$ once the subject entered the kitchen, the exhaust hood and makeup air were turned on when the stove was switched on. Air flow rate of the exhaust hood was $0.2 \mathrm{~m}^{3} / \mathrm{s}$. The supply air velocity for the conditioned system and makeup air was $1.4 \mathrm{~m} / \mathrm{s}$ and $1.2 \mathrm{~m} / \mathrm{s}$, respectively. Its corresponding air volume flow rate for the conditioned air and make-up air was $0.03 \mathrm{~m}^{3} / \mathrm{s}$ and $0.09 \mathrm{~m}^{3} / \mathrm{s}$, respectively. The rest air flow for the make-up air was supplied mainly from the infiltration. For the kitchen without ventilation system, the exhaust hood was turned on when the stove was switched on. External window and interior door were both closed during the cooking. Make-up air for the kitchen without ventilation system supplied mainly from the leakage. The total cooking period lasted around 20 minutes. During this time, we asked the subjects to vote their thermal sensations every minute. When the cooking was finished, the subject left the kitchen and went back to the preparation room to stay for another 10 minutes. Indoor parameters and skin temperature were continually measured during this time.

\subsection{Parameters measured}

All the subjects wore typical summer clothing, which is a combination of short sleeve, pants, underwear, socks and sneaker, with a clothing thermal resistance of 0.56 clo. Before the start of the experiment, each subject was asked the following information: gender, age, clothing, and their body weight were measured by using a weight scale (OMRON HBF-371).

During the cooking period, we asked the subjects to vote their thermal sensations every minute. The subjects voted for their thermal sensations by using the ASHRAE seven-point scale $(-3=$ cold, $-2=$ cool, $-1=$ slightly cool, $0=$ neutral, $1=$ slightly warm, $2=$ warm, and $3=$ 
hot). In order to understand the indoor thermal environment, this investigation used six ONSET HOBO MX1102 loggers and three HOBO U12-013 loggers to measure the indoor air temperature and relative humidity. The measurements were conducted at the left side of the subject $(\mathrm{P} 1)$ and in the middle of the kitchen $(\mathrm{P} 2)$ as shown in Fig. 2. At each location, the data was obtained at $0.1 \mathrm{~m}, 1.4 \mathrm{~m}$ and $1.7 \mathrm{~m}$ above the floor. We also further measured the air temperature in the Up, Middle, and Down positions near the right side of the stove. The measuring frequency was 5 seconds. The measured data was averaged every minute to be consistent with the TSV data. The HOBO loggers had a measuring accuracy of $\pm 0.2{ }^{\circ} \mathrm{C}$ for air temperature and $\pm 2 \%$ for relative humidity.

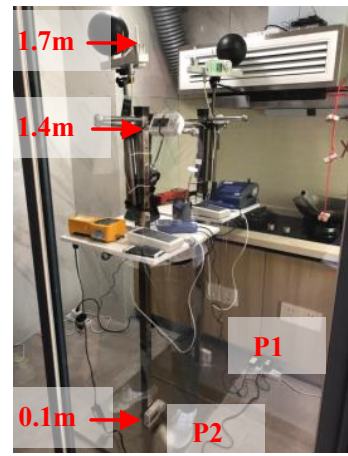

(a)

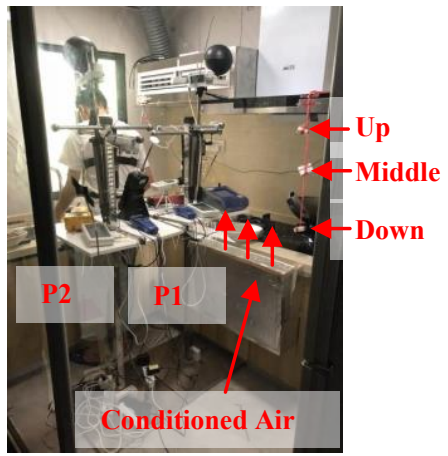

(b)
Fig. 2. Experimental kitchen (a) without and (b) with the new ventilation system.

To study the impact of kitchen thermal environment on a human body, we used 18 wireless button thermometers (DS1923) to measure the subjects' skin temperature on their different body parts, as shown in Figure 3. The measuring frequency was 5 seconds. The measured data was again averaged every minute. The wireless button thermometers had a measuring accuracy of $\pm 0.5^{\circ} \mathrm{C}$ for the skin temperature.

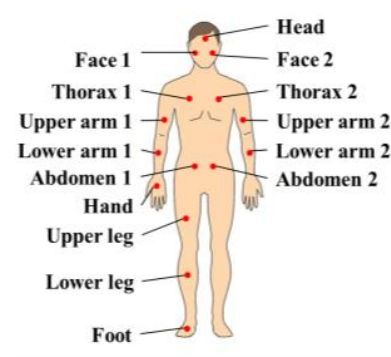

(a)
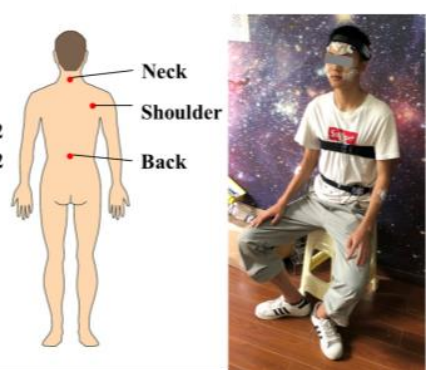

(b)
Fig. 3. (a) Measurement positions for skin temperatures, and (b) a test subject wearing the wireless button thermometers.

\section{Results}

This section describes (1) the outdoor and interior air temperature and relative humidity distributions of the kitchen with and without ventilation system, (2) the skin temperatures and thermal sensation votes under the two test conditions, and (3) correlations between the skin temperatures and the thermal sensation votes.

\subsection{Outdoor and interior air temperature and relative humidity distributions}

Table 1 shows the outdoor air temperature and relative humidity under the two test conditions with or without the ventilation system. The average outdoor air temperature and relative humidity for the test condition without ventilation system was $29.7^{\circ} \mathrm{C}$ and $61.6 \%$, respectively. The average outdoor air temperature and relative humidity for the test condition with ventilation system was $31.5^{\circ} \mathrm{C}$ and $59.3 \%$, respectively.

As shown in Table 1, although all tests were conducted in four consecutive days, outdoor environmental parameters were uncontrollably changing during the test period. Different outdoor test conditions would affect the tests from two aspects. On the one hand, environmental parameters of the make-up air system varied case to case. In addition, different outdoor conditions resulted in different initial indoor environment status of each test, as shown in Table 2. For the outdoor air supplied directly through the make-up air system to the kitchen, it will be exhausted by the exhaust hood quickly, which would have little impact on the subjects' thermal comfort. For the different initial indoor environment, we analyzed all parameters by comparing its relative variation during the test process based on the initial state, which can eliminate the influence of different initial state on thermal comfort.

Table 1. Outside environmental parameters for the 32 tests.

\begin{tabular}{|c|c|c|c|c|}
\hline \multirow{2}{*}{$\begin{array}{c}\text { Subject } \\
\text { No. }\end{array}$} & \multicolumn{2}{|c|}{ Without ventilation } & \multicolumn{2}{c|}{ With ventilation } \\
\cline { 2 - 5 } & $\begin{array}{c}\mathrm{T}_{\text {out }} \\
\left({ }^{\circ} \mathrm{C}\right)\end{array}$ & $\begin{array}{c}\mathrm{RH}_{\text {out }} \\
(\%)\end{array}$ & $\begin{array}{c}\mathrm{T}_{\text {out }} \\
\left({ }^{\circ} \mathrm{C}\right)\end{array}$ & $\begin{array}{c}\mathrm{RH}_{\text {out }} \\
(\%)\end{array}$ \\
\hline 01 & $\mathbf{2 8 . 0}$ & $\mathbf{5 2 . 2}$ & $\mathbf{3 4 . 6}$ & $\mathbf{5 4 . 4}$ \\
\hline 02 & $\mathbf{2 8 . 7}$ & $\mathbf{5 6 . 8}$ & $\mathbf{2 8 . 1}$ & $\mathbf{6 6 . 1}$ \\
\hline 03 & $\mathbf{3 0 . 2}$ & $\mathbf{5 1 . 0}$ & $\mathbf{3 2 . 2}$ & $\mathbf{5 2 . 2}$ \\
\hline 04 & $\mathbf{2 8 . 8}$ & $\mathbf{6 0 . 2}$ & $\mathbf{3 1 . 7}$ & $\mathbf{5 4 . 5}$ \\
\hline 05 & $\mathbf{2 8 . 1}$ & $\mathbf{6 3 . 1}$ & $\mathbf{3 1 . 5}$ & $\mathbf{5 5 . 3}$ \\
\hline 06 & $\mathbf{2 6 . 7}$ & $\mathbf{6 6 . 2}$ & $\mathbf{3 3 . 0}$ & $\mathbf{5 9 . 1}$ \\
\hline 07 & $\mathbf{2 6 . 2}$ & $\mathbf{7 1 . 3}$ & $\mathbf{2 9 . 0}$ & $\mathbf{6 5 . 6}$ \\
\hline 08 & $\mathbf{2 5 . 1}$ & $\mathbf{7 5 . 9}$ & $\mathbf{2 9 . 5}$ & $\mathbf{6 0 . 7}$ \\
\hline 09 & $\mathbf{2 4 . 9}$ & $\mathbf{7 8 . 6}$ & $\mathbf{2 9 . 9}$ & $\mathbf{6 2 . 4}$ \\
\hline 10 & $\mathbf{3 0 . 9}$ & $\mathbf{6 4 . 3}$ & $\mathbf{3 5 . 6}$ & $\mathbf{5 0 . 5}$ \\
\hline 11 & $\mathbf{3 3 . 4}$ & $\mathbf{5 5 . 9}$ & $\mathbf{3 1 . 2}$ & $\mathbf{6 4 . 0}$ \\
\hline 12 & $\mathbf{3 6 . 1}$ & $\mathbf{4 5 . 3}$ & $\mathbf{3 4 . 8}$ & $\mathbf{5 3 . 2}$ \\
\hline 13 & $\mathbf{3 5 . 5}$ & $\mathbf{4 8 . 7}$ & $\mathbf{3 3 . 6}$ & $\mathbf{5 6 . 5}$ \\
\hline 14 & $\mathbf{3 3 . 4}$ & $\mathbf{5 5 . 6}$ & $\mathbf{2 9 . 1}$ & $\mathbf{6 6 . 4}$ \\
\hline 15 & $\mathbf{2 9 . 8}$ & $\mathbf{6 6 . 6}$ & $\mathbf{3 0 . 4}$ & $\mathbf{6 3 . 6}$ \\
\hline 16 & $\mathbf{2 9 . 4}$ & $\mathbf{6 6 . 5}$ & $\mathbf{2 9 . 7}$ & $\mathbf{6 4 . 6}$ \\
\hline
\end{tabular}

Table 2 shows the indoor air temperature and relative humidity at the beginning of the cooking, under the two test conditions with or without the ventilation system. The average indoor air temperature and relative humidity 
for the test condition without ventilation system was $29.3^{\circ} \mathrm{C}$ and $62.2 \%$, respectively. The average indoor air temperature and relative humidity for the test condition with ventilation system was $29.2^{\circ} \mathrm{C}$ and $66.4 \%$, respectively.

Table 2. Indoor environmental conditions at the beginning of the cooking for the 32 tests.

\begin{tabular}{|c|c|c|c|c|}
\hline \multirow{2}{*}{$\begin{array}{c}\text { Subject } \\
\text { No. }\end{array}$} & \multicolumn{2}{|c|}{ Without ventilation } & \multicolumn{2}{c|}{ With ventilation } \\
\cline { 2 - 5 } & $\begin{array}{c}\mathrm{T}_{\text {in }} \\
\left({ }^{\circ} \mathrm{C}\right)\end{array}$ & $\begin{array}{c}\mathrm{RH}_{\text {in }} \\
(\%)\end{array}$ & $\begin{array}{c}\mathrm{T}_{\text {in }} \\
\left({ }^{\circ} \mathrm{C}\right)\end{array}$ & $\begin{array}{c}\mathrm{RH}_{\text {in }} \\
(\%)\end{array}$ \\
\hline 01 & $\mathbf{2 8 . 8}$ & $\mathbf{5 6 . 6}$ & $\mathbf{3 1 . 6}$ & $\mathbf{6 2 . 8}$ \\
\hline 02 & $\mathbf{2 6 . 5}$ & $\mathbf{6 6 . 8}$ & $\mathbf{2 4 . 3}$ & $\mathbf{8 1 . 5}$ \\
\hline 03 & $\mathbf{2 8 . 1}$ & $\mathbf{5 7 . 2}$ & $\mathbf{2 7 . 6}$ & $\mathbf{7 0 . 0}$ \\
\hline 04 & $\mathbf{2 8 . 9}$ & $\mathbf{5 8 . 9}$ & $\mathbf{2 8 . 8}$ & $\mathbf{6 5 . 0}$ \\
\hline 05 & $\mathbf{2 8 . 6}$ & $\mathbf{6 0 . 4}$ & $\mathbf{2 9 . 2}$ & $\mathbf{6 3 . 0}$ \\
\hline 06 & $\mathbf{2 8 . 2}$ & $\mathbf{6 1 . 3}$ & $\mathbf{2 9 . 4}$ & $\mathbf{7 0 . 8}$ \\
\hline 07 & $\mathbf{2 7 . 7}$ & $\mathbf{6 4 . 5}$ & $\mathbf{2 9 . 7}$ & $\mathbf{6 5 . 3}$ \\
\hline 08 & $\mathbf{2 7 . 1}$ & $\mathbf{6 8 . 7}$ & $\mathbf{2 6 . 0}$ & $\mathbf{7 6 . 0}$ \\
\hline 09 & $\mathbf{2 7 . 1}$ & $\mathbf{6 9 . 2}$ & $\mathbf{2 9 . 6}$ & $\mathbf{6 1 . 9}$ \\
\hline 10 & $\mathbf{2 6 . 4}$ & $\mathbf{7 5 . 0}$ & $\mathbf{3 0 . 9}$ & $\mathbf{6 4 . 3}$ \\
\hline 11 & $\mathbf{2 8 . 3}$ & $\mathbf{6 8 . 9}$ & $\mathbf{2 9 . 1}$ & $\mathbf{6 5 . 3}$ \\
\hline 12 & $\mathbf{3 1 . 4}$ & $\mathbf{5 8 . 2}$ & $\mathbf{3 0 . 1}$ & $\mathbf{6 9 . 1}$ \\
\hline 13 & $\mathbf{3 2 . 6}$ & $\mathbf{5 8 . 0}$ & $\mathbf{3 0 . 1}$ & $\mathbf{6 3 . 2}$ \\
\hline 14 & $\mathbf{3 3 . 8}$ & $\mathbf{5 6 . 0}$ & $\mathbf{3 0 . 9}$ & $\mathbf{5 7 . 2}$ \\
\hline 15 & $\mathbf{3 3 . 1}$ & $\mathbf{5 6 . 5}$ & $\mathbf{3 0 . 0}$ & $\mathbf{6 1 . 9}$ \\
\hline 16 & $\mathbf{3 2 . 6}$ & $\mathbf{5 8 . 3}$ & $\mathbf{2 9 . 5}$ & $\mathbf{6 4 . 5}$ \\
\hline & & & & \\
\hline
\end{tabular}

This investigation first compared the indoor and outdoor air temperature and relative humidity distributions under the two test conditions with or without the ventilation system. Due to the space limitation of the paper, we took two tests of a subject as example. Figure 4 shows the outdoor and indoor air temperature and relative humidity distributions in the kitchen under the test condition without the ventilation system. The reason why the initial indoor air temperature was much lower than the outdoor temperature was probably because the airconditionings were switched on in its surrounding rooms. And there was only one external wall existed in the kitchen. Indoor air temperature and relative humidity were stable at the first 13 minutes when the subject was preparing for cooking, including washing and cutting vegetables and meat, etc. The indoor air temperature began to rise when the subject turned on the stove for cooking and it continuously to rise with the cooking process. The air temperature at the "Down" position was the highest because it was most close to the stove as shown in Figure 2. It rose by $6.3 \mathrm{~K}$ compared from its initial temperature at the beginning of the cooking. Without the ventilation system, the waste heat cannot be removed effectively. During the cooking, the subject stood in front of the stove. High temperature in front of the subject would affect the subject's thermal sensation. In addition, the air temperature stratification existed in the kitchen. The maximum air temperature difference (difference between the maximum air temperature occurred during the cooking and the initial air temperature at the beginning of the cooking) was $4.0 \mathrm{~K}$ between P1-0.1m and P1-1.4m, and $2.9 \mathrm{~K}$ between P2$0.1 \mathrm{~m}$ and $\mathrm{P} 2-1.4 \mathrm{~m}$. It can be found that the air temperature around the subject was highly non-uniform. The relative humidity did not show significant difference in both $\mathrm{P} 1$ and $\mathrm{P} 2$. While the relative humidity at the stove locations (Up, Middle, Down) began to decrease were when the subject turned on the stove for cooking and it continuously decreased with the cooking process, which was reasonable because of the rise of the air temperature.

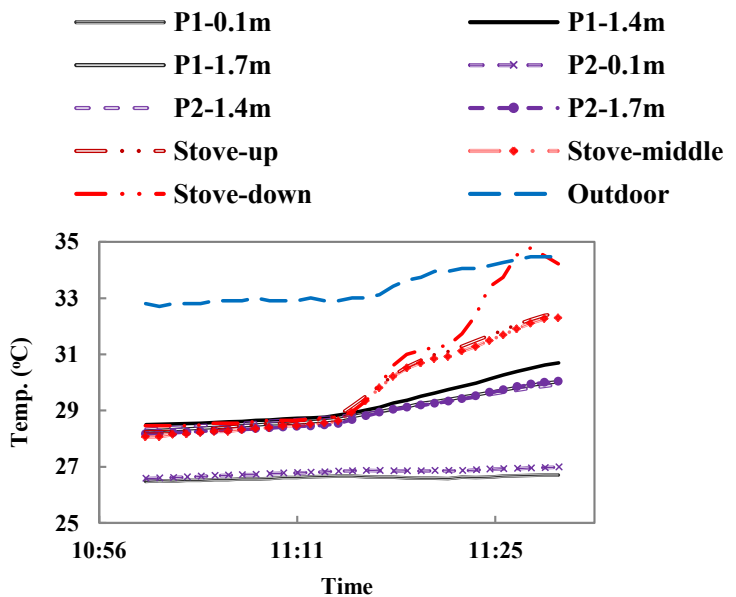

(a)

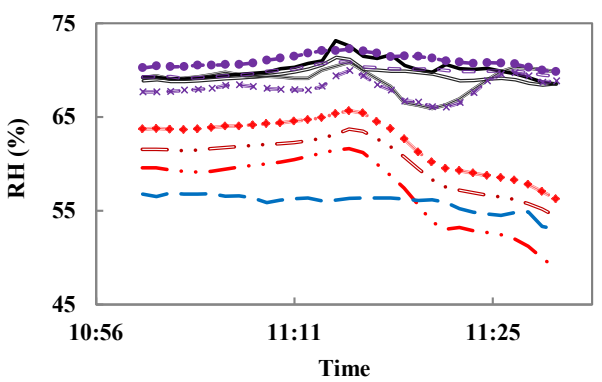

(b)

Fig. 4. Environmental parameters distribution under the condition without ventilation system: (a) outdoor and indoor air temperature distributions, and (b) outdoor and indoor relative humidity distributions.

Figure 5 shows the outdoor and indoor air temperature and relative humidity distributions in the kitchen under the test condition with the ventilation system. The air temperatures close to the stove (Up, Middle, Down) were gradually decreased due to the conditioned air supplied from the lower part of cabinet under the cooking stove at the first 14 minutes. They began to rise when the subject turned on the stove for cooking. They first rose was at 09:49, then decreased and then rose again at 09:56. It was due to the turning on and closed off the stove. The air temperature at the "Down" position rose only $1.9 \mathrm{~K}$. With the new ventilation system, the air temperatures at $\mathrm{P} 1$ and $\mathrm{P} 2$ decreased gradually during the cooking process. The relative humidity at all indoor locations decreased during the cooking process. For the positions at the stove, the humidity decreased due to the increase of the air temperature there. The reason why the 
relative humidity at $\mathrm{P} 1$ and $\mathrm{P} 2$ also decreased was probably due to influence of the low relative humidity of the supplied conditioned air. It can be concluded that the ventilation system could effectively improve the thermal environment in the kitchen.

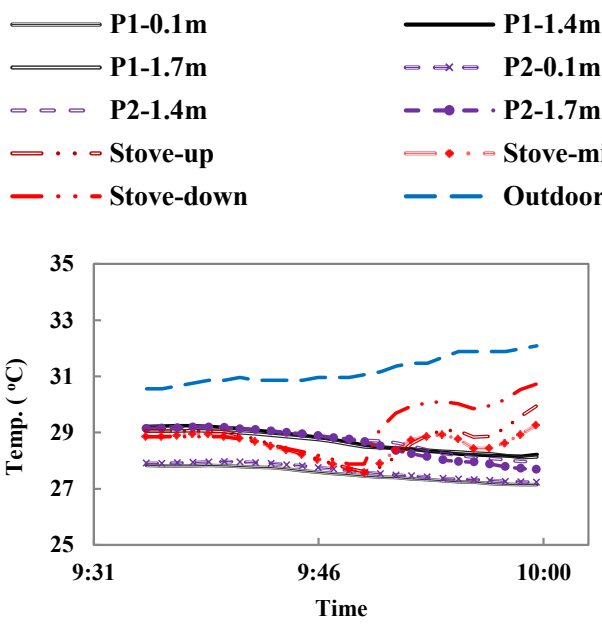

(a)

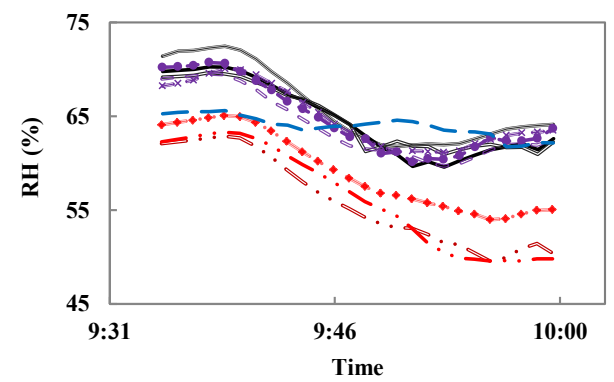

(b)

Fig. 5. Environmental parameters distribution under the condition with ventilation system: (a) outdoor and indoor air temperature distributions, and (b) outdoor and indoor relative humidity distributions.

Figure 6 depicts the maximum air temperature increase (difference between the maximum air temperature occurred during the cooking and the initial air temperature at the beginning of the cooking) at P1-1.4m between the beginning and the end of the cooking process, with and without using ventilation system. The indoor air temperature increase without the ventilation system was 2.5 times higher than that with the ventilation system.

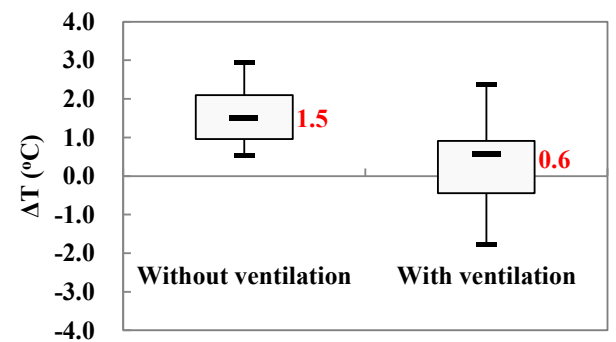

Fig. 6. Indoor air temperature increase at P1-1.4m between the beginning and the end of the cooking process: (a) without the ventilation system, (b) with the ventilation system. The horizontal lines represents the $10^{\text {th }}, 25^{\text {th }}, 50^{\text {th }}$ (the median), $75^{\text {th }}$, and $90^{\text {th }}$ percentiles.

\subsection{Skin temperature $\left(\mathrm{T}_{\mathrm{sk}}\right)$ and thermal sensation vote (TSV)}

This investigation further compared the skin temperature and thermal sensation vote under two test conditions with or without the ventilation system of the same subject as mentioned in section 3.1. Figures 7(a), 7(c), $7(\mathrm{e})$ and $7(\mathrm{~g})$ show the skin temperatures at forehead, face, thorax and upper leg and the subject's TSV. TSV rose as the skin temperature became higher. The maximum increase (difference between the maximum skin temperature occurred during the cooking and the initial skin temperature at the beginning of the cooking) in skin temperature at those four body parts was 2.5, 3.0, 2.5 and $0.5 \mathrm{~K}$, respectively. Figures 7(b), 7(d), 7(f) and 7(h) show the skin temperatures and TSV with the ventilation system. The skin temperature increased at the first 14 minutes and then decreased. The possible reason is that the subject turned on the exhaust hood and the make-up air system at that time, which could further remove some waste heat. The maximum increase in skin temperature at those four body parts was $1.3,0.8,0.9$ and $0.2 \mathrm{~K}$, respectively, which was much lower than that without the ventilation system. Although the skin temperature rose at the first time, the subject's TSV remained at 0 . It demonstrated that the subject's thermal sensation was effectively improved with the new ventilation system.

Without the new ventilation system, all cooks complained that the hottest parts were head, face and thorax areas. It was because those regions were close to the stove and had the greatest exposure to the high air and radiant temperatures. With the new ventilation system, conditioned air in front of the cook improved the thermal sensation of the subjects on those body parts. Subjects' thermal sensation mainly remained neutral or slightly warm. It seems that local thermal sensation had a great influence on the whole body sensation.

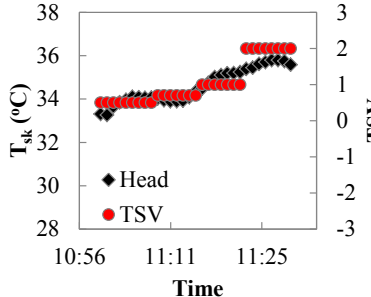

(a)

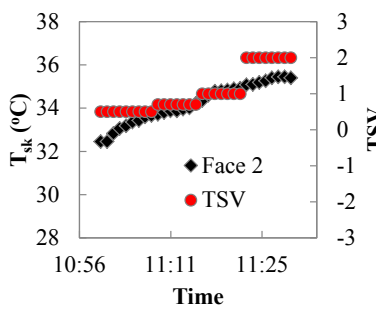

(c)

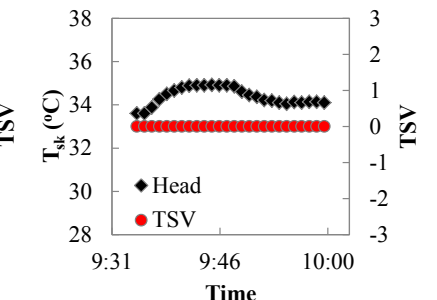

(b)

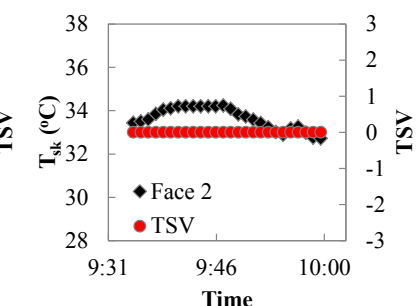

(d) 


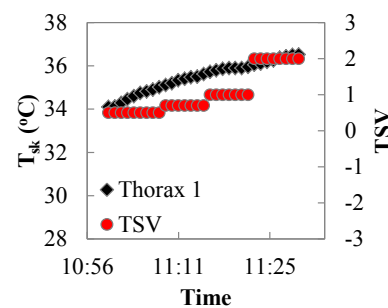

(e)

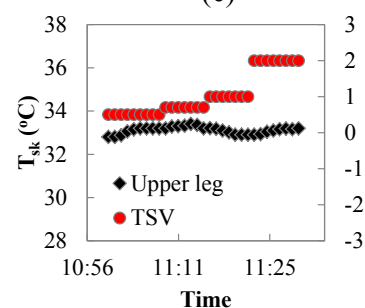

(g)

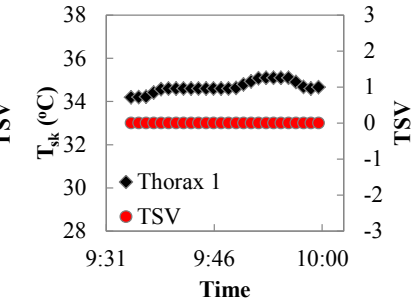

(f)

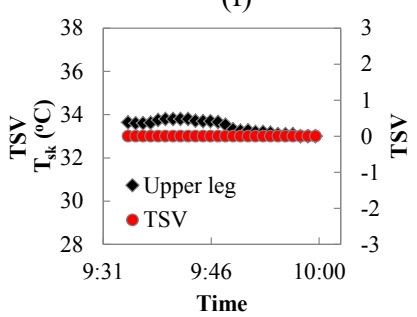

(h)
Fig. 7. Skin temperature and TSV over time: left - without the new ventilation system; right - with the ventilation system.

Figure 8 depicts the maximum skin temperature increase (difference between the maximum skin temperature occurred during the cooking and the initial skin temperature at the beginning of the cooking) at different body parts with and without the ventilation system. As shown in Figure 8(a), due to the radiation from the stove, the skin temperature increase was highest at the head region with a medium of $3.4 \mathrm{~K}$. Compared with the front-upper body part of the subject, the lower and back body parts were less affected by the stove. The high radiation asymmetry would make thermal comfort of the subject deteriorated. The cooks complained that the hottest parts were thorax, head and face areas without the new ventilation system. Figure 8(b) shows the maximum skin temperature increase at different body parts with the ventilation system. The ventilation could effectively reduce in skin temperature increase for all the body parts compared with that without the ventilation system. The cooks also reflected that the ventilation system had made the thermal environment much more comfortable, and among whom only one cook mentioned about little draft caused by the ventilation system. The ventilation system could effectively improve the thermal environment in the kitchen.

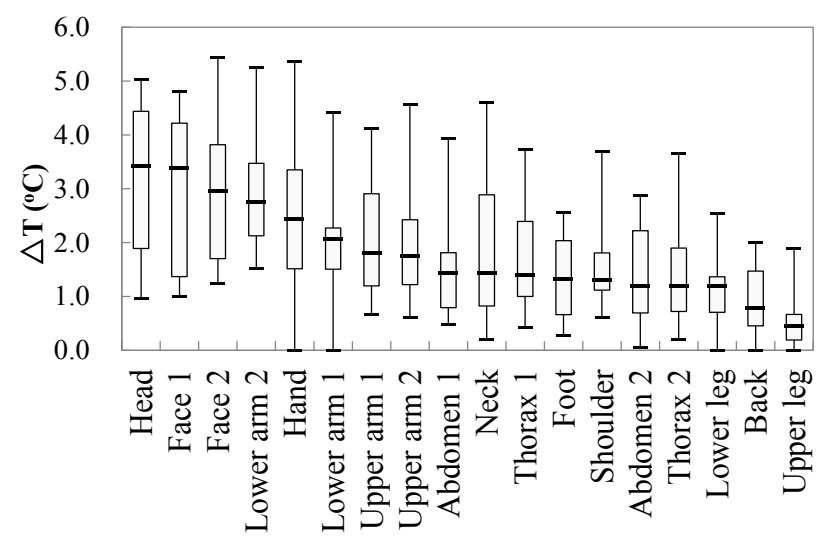

(a)

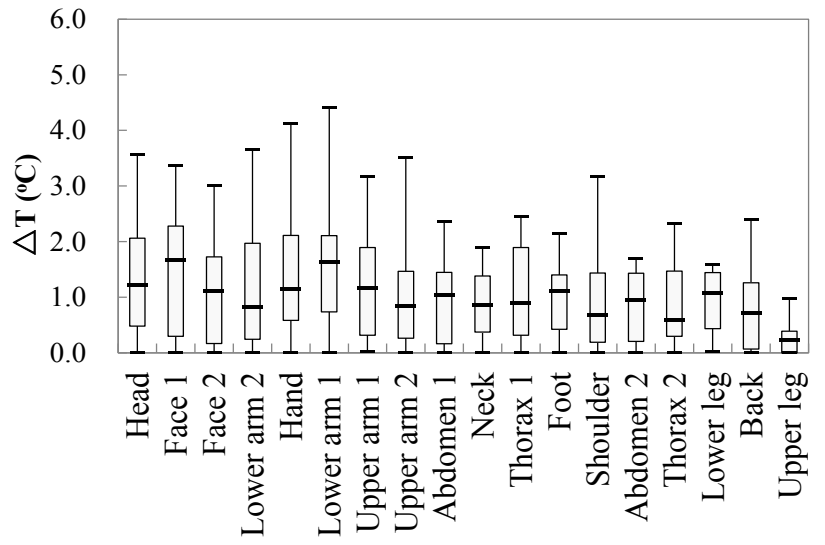

(b)

Fig. 8. The skin temperature increase at different body parts (a) without the ventilation system, and (b) with the ventilation system. The horizontal lines represents the $10^{\text {th }}, 25^{\text {th }}, 50^{\text {th }}$ (the median), $75^{\text {th }}$, and $90^{\text {th }}$ percentiles.

\subsection{Correlations between $T_{s k}$ and TSV}

This investigation also explored the correlations between the skin temperature and TSV. Figure 9(a) depicts reasonably well correlations between the skin temperatures and TSV without the ventilation system. The body part most associated with the TSV was the thorax. It was also coincided with the thermal discomfort region where the cooks mentioned. Figure 9(b) shows the correlations between the skin temperatures and TSV with the ventilation system. Although the skin temperature rose slightly during the cooking process and may decline due to the operation of the exhaust hood and make-up air system, subjects' thermal sensation mainly remained neutral or slightly warm. Therefore, the correlations between the skin temperatures and TSV under this test condition were much lower compared with that without the ventilation system. One possible reason is that the environment was neutral so that thermal sensation was satisfactory. Since thermal comfort is also a function of air wind velocity, relative humidity, more parameters should be measured for a more meaningful analysis.

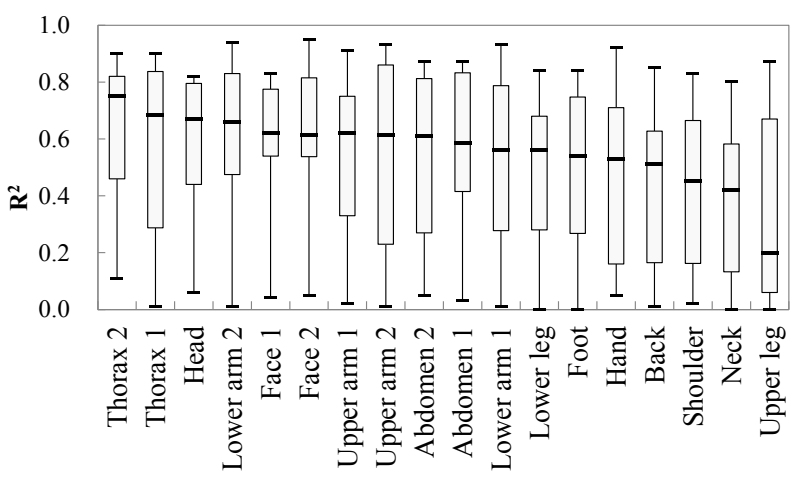

(a) 


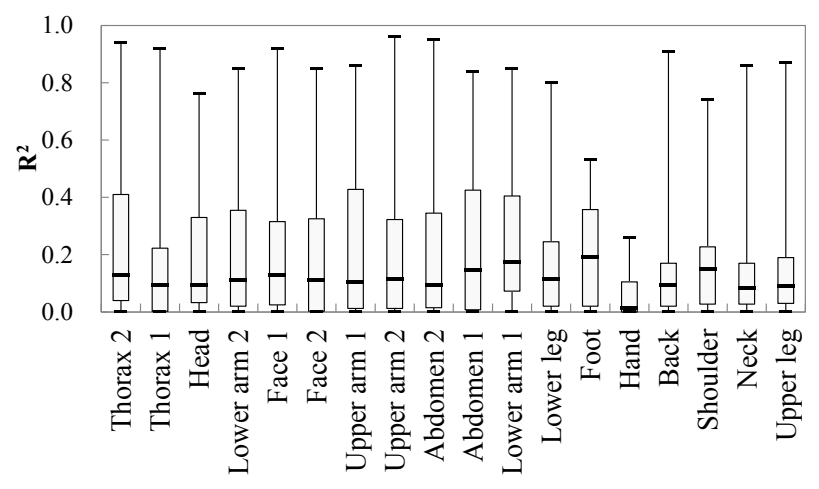

(b)

Fig. 9. Correlations between skin temperature and TSV (a) without the ventilation system, and (b) with the ventilation system. The horizontal lines represents the $10^{\text {th }}, 25^{\text {th }}, 50^{\text {th }}$ (the median), $75^{\text {th }}$, and $90^{\text {th }}$ percentiles.

\section{Discussions}

Although we conducted all test in four consecutive days, outdoor and indoor environmental parameters were uncontrollably changing during the test period. It is best to construct an environmental chamber surrounded the kitchen, which can be used to control the environmental parameters inside and outside the kitchen. But it would increase much more costs.

Although we used same group of subjects to compare the thermal performance of the new ventilation system, and we asked the subjects to cook the same dishes, the cooking time and cooking process from entering to leaving the kitchen was somewhat different from person to person. We were unable to estimate the errors that may have caused.

Our investigation primarily measured the air temperature and relative humidity around the subject, the wall temperature, the outdoor air temperature etc. We did not measure the flow field inside the kitchen, which was also an important factor to human's thermal comfort.

The subject sample size was somewhat limited, and it did not encompass a wide variety of ages, weights, or other factors. Indraganti [14] found that thermal sensitivity changed with age, gender and economic group.

\section{Conclusions}

This investigation used human subject tests to assess the thermal comfort level in a Chinese kitchen with a new ventilation system. The study led to the following conclusions:

- Thermal environment was effectively improved with the new ventilation system. Indoor air temperature increase without the ventilation system was 2.5 times higher than that with the ventilation system.

- The thermal environment in the kitchen was nonuniform. The subjects' local thermal sensation had a great influence on the whole body sensation. Without the new ventilation system, the subjects complained that the hottest parts were thorax, head and face areas.
- Reasonably good correlation existed between the cooks' skin temperatures and their thermal sensation votes without using the ventilation system. With the new ventilation system, no clear correlations existed between the skin temperatures and TSV since the environment was neutral.

The research presented in this paper was partially supported by the National Key R\&D Program from the Ministry of Science and Technology, China, on "Green Buildings and Building Industrialization" through Grant No. 2016YFC0700500 and by the National Natural Science Foundation of China through Grant No. 51678395. We would like to express our gratitude to Jiawei Tang and Tao Zhang from Vanke real estate development co. Itd, Changsha Vanke; Yan Zhou and Yujia Qiu from XiangYa School of Medicine, Central South University; for their help in collecting data for the investigation.

\section{References}

1. C.M. Lai. Building Services Engineering Research and Technology. 26, 157-166 (2005) .

2. P. Wei, B. Zhou, M. Tan, F. Li, J. Lu, Z. Dong, G. Wang, Y. Xiao. Procedia Engineering. 205, 20412048 (2017).

3. ISO. 2005. ISO Standard 7730:2005. Geneva, Switzerland: International Organization for Standardization.

4. ASHRAE. 2014. ANSI/ASHRAE Standard 55-2014. Atlanta: ASHRAE, Inc.

5. H. Wang, J. Hu, C. Huang, K. Chen, W. Gu, M. Shi. The 6th International Conference on Indoor Air Quality, Ventilation \& Energy Conservation in Buildings. (IAQVEC Oct. 28-31, Sendai, Japan, 2007)

6. C. Chiang, C. Lai, P. Chou, Y. Li. B\&E. 35, 579-585 (2000).

7. D.P. Wyon. Proceedings of Indoor Air (Institute of Public Health, Tokyo, 1996)

8. Y. Zhao, A. Li, R. Gao, P. Tao, J. Shen. E\&B. 69, 544-561 (2014).

9. A. Livchak, D. Schrock, Z. Sun. ASHRAE Transactions. 111(1),748-54 (2005).

10. A. Simone, B.W. Olesen, J. L. Stoops, A.W. Watkins. HVAC\&R Research. 19, 1001-1015 (2013).

11. L. Zhu, J. Wang, B. Jiang. China Environment Science, 22(2), 142-145 (2002).

12. X. Liu, X. Wang, G. Xi. Journal of Occupational and Environmental Hygiene. 11(3), 186-199 (2014),

13. C. Cao, J. Gao, L. Wu, X. Ding, X. Zhang. Indoor and Built Environment. 26(2), 226-237 (2017).

14. M. Indraganti, KD. Rao. E\&B. 42, 273-281 (2010). 